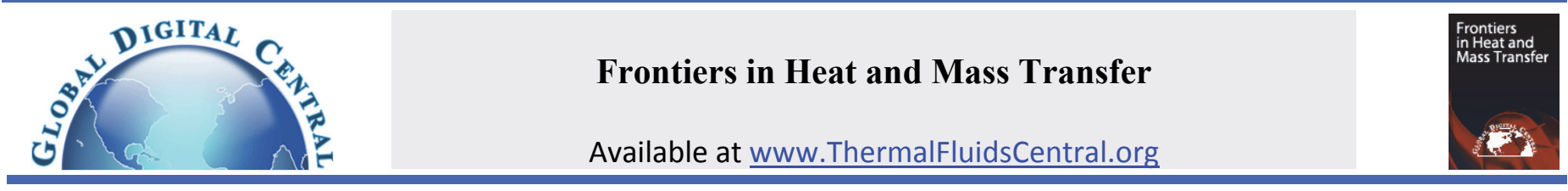

\title{
MHD MIXED CONVECTION STAGNATION POINT FLOW TOWARDS A STRETCHING SHEET IN THE PRESENCE OF DUFOUR EFFECT, RADIATION EFFECT AND WITH VARIABLE FLUID VISCOSITY
}

\author{
Vandana Bisht* \\ Department of Mathematics, AITS, Amrapali Group of Institutes, Haldwani- 263139, Uttarakhand, India
}

\begin{abstract}
In this paper the steady laminar magneto hydrodynamic (MHD) mixed convection boundary layer flow towards a vertical stretching sheet with variable fluid viscosity, radiation and in the presence of Dufour's effect have been investigated. The governing partial differential equations are transformed into set of ordinary differential equations using similarity transformation, and then these equations have been solved numerically using Runge- Kutta method with shooting technique. Results shows that magnitude of skin friction coefficient decreases, while magnitude of heat transfer coefficient and mass transfer coefficient increases with decreasing values of viscosity variation parameter for the case of opposing flow. But in the case of assisting flow magnitude of skin friction coefficient, heat transfer coefficient and mass transfer coefficient decreases with decreasing values of viscosity parameter. Also magnitude of skin friction coefficient and heat transfer coefficient decreases with increasing values of Dufour number for both assisting and opposing flow, and there is a slight change in magnitude of mass transfer coefficient with Dufour number. Magnitude of velocity increases with increasing values of Dufour number for both assisting and opposing flow.
\end{abstract}

Keywords: Dufour's effect, MHD flow, stretching sheet, similarity transformation, shooting technique.

\section{INTRODUCTION}

Heat and mass transfer mixed convection boundary layer flow along a continuously stretching sheet has attracted considerable attention in the last several decades, due to its application in extrusion process, wire and fiber coating, polymer processing, foodstuff processing, design of various heat exchangers and chemical processing equipment etc.

Mahapatra and Gupta presented the heat transfer stagnation point flow towards a stretching sheet in 2002. In 2005, Sedeek and Salem studied the effect of variable viscosity and variable thermal diffusivity in laminar mixed convection boundary layer flow adjacent to a vertical continuously stretching sheet. Ishak presented the mixed convection boundary layer flow near the two dimensional stagnation point flow of an incompressible fluid over a stretching sheet in 2006. In 2007 El-Aziz studied the heat and mass transfer of electrically conducting fluid having temperature dependent viscosity and thermal conductivity along a stretching sheet with the effect of Ohmic heating.. In 2008 Ishak, Nazar and Pop presented the MHD flow and heat transfer along a stretching vertical sheet. In $2009 \mathrm{Pal}$ D. studied effect of thermal radiation on heat and mass transfer stagnation point flow towards a stretching sheet. Effects of variable properties on MHD heat and mass transfer flow near a stagnation point towards a stretching sheet in a porous medium with thermal radiation was studied by Salema \& Fathy in 2012. Numerical investigation of stagnation point flow over a stretching sheet with convective boundary conditions was presented by Mohmed, Salleh, Nazar \& Ishak in 2013. In 2016 MHD flow due to a linearly stretching sheet with induced magnetic field was studied by El-Mistikawy.
It have been seen that in previous studies the Dufour effect was neglected on the basis that of a smaller order of magnitude than the effects described by Fourier's and Fick' laws. However, in their book, Eckert and Drake (1972) have reported several cases when the Dufour effect cannot be neglected. So aim of this paper is to study the effect of heat and mass transfer in mixed convection boundary layer flow along a stretching sheet in the presence of magnetic field, Dufour effect and Radiation effect with variable fluid viscosity. It is assumed that the stretching velocity, surface temperature and surface concentration vary linearly with the distance from stagnation point. The governing fluid flow equations are transformed into non dimensional form using similarity transformation and solved by using Runge- Kutta method with shooting technique.

\section{PROBLEM FORMULATION}

The mixed convection, two-dimensional, laminar, boundary layer flow due to a stretching vertical heated sheet in a viscous, incompressible and electrically conducting fluid in the presence of magnetic field and with Dufour effect has been made. Two equal and opposite forces are impulsively applied along the x-axis so that the sheet is stretched, keeping the origin fixed in the fluid of ambient temperature $\mathrm{T}_{\infty}$. The transverse magnetic field $\mathrm{B}_{0}$ is applied along perpendicular direction of $\mathrm{x}$ - axis. The stationary coordinate system has its origin located at the centre of the sheet with the $\mathrm{x}$-axis extending along the sheet, while the $\mathrm{y}$ axis is measured normal to the surface of the sheet and in the positive

${ }^{*}$ Email: vandanabisht7@gmail.com 
direction from the sheet to the fluid. The coordinate system has been shown in figure.

The stretching velocity $u_{w}(x)$, surface temperature $T_{w}(x)$ and surface concentration $\mathrm{C}_{\mathrm{w}}(\mathrm{x})$ vary linearly with the distance from stagnation point O. The governing fluid flow equations for the problem under consideration are:

Equation of continuity,

$$
\frac{\partial \mathrm{u}}{\partial \mathrm{x}}+\frac{\partial \mathrm{v}}{\partial \mathrm{y}}=0
$$

Equation of momentum,

$\mathrm{u} \frac{\partial \mathrm{u}}{\partial \mathrm{x}}+\mathrm{v} \frac{\partial \mathrm{u}}{\partial \mathrm{y}}=\mathrm{u}_{\mathrm{e}} \frac{\partial \mathrm{u}_{\mathrm{e}}}{\partial \mathrm{x}}+\frac{1}{\rho} \frac{\partial}{\partial \mathrm{y}}\left(\mu^{\prime} \frac{\partial \mathrm{u}}{\partial \mathrm{y}}\right) \pm \mathrm{g} \beta_{\mathrm{T}}\left(\mathrm{T}-\mathrm{T}_{\infty}\right) \pm \mathrm{g} \beta_{\mathrm{C}}\left(\mathrm{C}-\mathrm{C}_{\infty}\right)+$

$\frac{\sigma B_{0}^{2}}{\rho}\left(u_{e}-u\right)$

Equation of heat transfer,

$u \frac{\partial T}{\partial x}+v \frac{\partial T}{\partial y}=\frac{1}{\rho C_{p}} \frac{\partial}{\partial y}\left(k \frac{\partial T}{\partial y}\right)+\frac{\mu^{\prime}}{\rho C_{p}}\left(\frac{\partial u}{\partial y}\right)^{2}-\frac{1}{\rho C_{p}} \frac{\partial \mathrm{q}_{r}}{\partial y}+\frac{D_{k}}{C_{s} C_{p}}$

Equation of mass transfer,

$\mathrm{u} \frac{\partial \mathrm{C}}{\partial \mathrm{x}}+\mathrm{v} \frac{\partial \mathrm{C}}{\partial \mathrm{y}}=\mathrm{D} \frac{\partial^{2} \mathrm{C}}{\partial \mathrm{z}^{2}}$

Here $\mathrm{u}$ and $\mathrm{v}$ are velocity component along $\mathrm{x}$ and $\mathrm{y}$ direction. $\mathrm{g}$ is acceleration due to gravity, $\mathrm{T}$ and $\mathrm{C}$ are temperature and concentration of fluid, $\mathrm{k}$ is thermal conductivity of fluid, $\mu^{\prime}$ is variable fluid viscosity, $\mathrm{k}_{\mathrm{t}}$ is thermal diffusion ratio and $\mathrm{D}$ is mass diffusion coefficient. In equation (2) "+" sign is corresponding to assisting flow and "-_sign refers to an opposing flow. The stretching surface has temperature $T_{w}$, concentration $\mathrm{C}_{\mathrm{w}}$ and the free stream temperature and concentration are $\mathrm{T}_{\infty}$ and $\mathrm{C}_{\infty}$ respectively, with $\mathrm{T}_{\mathrm{w}}>\mathrm{T}_{\infty}$ and $\mathrm{C}_{\mathrm{w}}>\mathrm{C}_{\infty}$. In this study the radiation heat flux in the $\mathrm{x}$-direction has also been considered. Using Rosseland diffusion approximation the radiation heat flux is given by:

$\mathrm{q}_{\mathrm{r}}=-\frac{4 \sigma^{*}}{3 \mathrm{k}^{*}} \frac{\partial \mathrm{T}^{4}}{\partial \mathrm{y}}$

As done by Raptis in 1998 in his work here also the temperature difference within the flow is assumed to be sufficiently small so that $\mathrm{T}^{4}$ may be expressed as a linear function of temperature $T$, i.e.

$\mathrm{T}^{4} \cong 4 \mathrm{~T}_{\infty}^{3} \mathrm{~T}-3 \mathrm{~T}_{\infty}^{4}$

From equation (3) and in view of equation number (5) and (6), it is seen that the effect of radiation is to enhance the thermal diffusivity.

The initial and boundary conditions are:

$\mathrm{u}=\mathrm{u}_{\mathrm{w}}(\mathrm{x})=\mathrm{U}_{0} \mathrm{x}, \mathrm{v}=\mathrm{v}_{\mathrm{w}}(\mathrm{x}), \mathrm{T}=\mathrm{T}_{\mathrm{w}}(\mathrm{x})=\mathrm{T}_{\infty}+\mathrm{bx}, \quad \mathrm{C}=\mathrm{C}_{\mathrm{w}}(\mathrm{x})=\mathrm{C}_{\infty}+\mathrm{dx}$, at $\mathrm{y}=0$ $\mathrm{u}=\mathrm{u}_{\mathrm{e}}(\mathrm{x})=\mathrm{ax}, \mathrm{T} \rightarrow \mathrm{T}_{\infty}, \mathrm{C} \rightarrow \mathrm{C}_{\infty}$, as $\mathrm{y} \rightarrow \infty$

Here $\mathrm{U}_{0}, \mathrm{a}, \mathrm{b}, \mathrm{d}$ are constants. $\mathrm{v}_{\mathrm{w}}$ is suction velocity and $\mathrm{u}_{\mathrm{e}}$ is velocity of the flow external to the boundary layer.

The similarity transformations used are:

$\psi=\left(\mathrm{U}_{0} v\right)^{\frac{1}{2}} \mathrm{X} \mathrm{f}(\eta), \eta=\left(\frac{\mathrm{U}_{0}}{v}\right)^{\frac{1}{2}} \mathrm{y}$

$u=\frac{\partial \psi}{\partial y}, v=-\frac{\partial \psi}{\partial x}$

$\theta(\eta)=\frac{\mathrm{T}-\mathrm{T}_{\infty}}{\mathrm{T}_{\mathrm{w}}-\mathrm{T}_{\infty}}, \varnothing(\eta)=\frac{\mathrm{C}-\mathrm{C}_{\infty}}{\mathrm{C}_{\mathrm{w}}-\mathrm{C}_{\infty}}$ and $\mu^{\prime}=\mu \mathrm{e}^{-\gamma \theta}$

here $\psi$ is stream function, $\eta$ is similarity variable, $\theta$ and $\varnothing$ are dimensionless temperature and concentration.

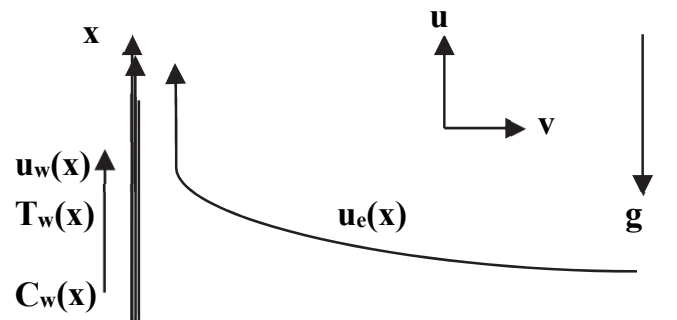

Buoyancy assisting region

$\mathbf{O}$ $\mathbf{y}$

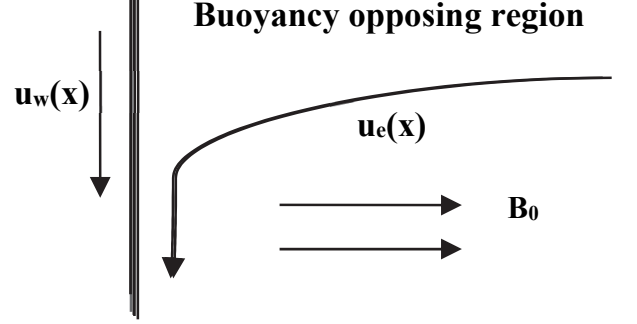

Fig. 1 Physical model

Equation (5) and (6) with similarity transformations (8) will be used to convert equation (3) into ordinary differential equation. Also by using above transformations equations (2) - (4) are converted into following set of ordinary differential equations:

$\mathrm{f}^{\prime \prime \prime}+\left[\left(\frac{\mathrm{a}}{\mathrm{U}_{0}}\right)^{2}-\mathrm{f}^{2}+\mathrm{ff} \mathrm{f}^{\prime \prime}+\mathrm{M}^{2}\left(\frac{\mathrm{a}}{\mathrm{U}_{0}}\right)-\mathrm{M}^{2} \mathrm{f}^{\prime} \pm \lambda \theta \pm \delta \varnothing\right] \mathrm{e}^{\gamma \theta}-\gamma \theta^{\prime} \mathrm{f}^{\prime \prime}=$

0

$\theta^{\prime \prime}+\frac{4}{3} \operatorname{Rd}\left[1+\left(\theta_{\mathrm{w}}-1\right) \theta\right]^{3} \theta^{\prime \prime}+4 \mathrm{Rd}\left[1+\left(\theta_{\mathrm{w}}-1\right) \theta\right]^{2} \theta^{\prime 2}\left(\theta_{\mathrm{w}}-1\right)+$

$\operatorname{Pr}\left[\mathrm{f}^{\prime}-\mathrm{f}^{\prime} \theta+\operatorname{Du} \emptyset^{\prime \prime}\right]=0$

$\operatorname{Sc}\left(f \emptyset^{\prime}-f^{\prime} \emptyset\right)+\emptyset^{\prime \prime}=0$

Here Sc is Schmidt number, Du is Dufour number, $\lambda$ is thermal buoyancy parameter, $\delta$ is solutal buoyancy parameter and $\gamma$ is non dimensional viscosity variation parameter.

The transformed boundary conditions are

$\mathrm{f}^{\prime}(0)=1, \quad \mathrm{f}(0)=0, \quad \theta(0)=1$ and $\varnothing(0)=1$ at $\eta=0$

$\mathrm{f}=\frac{\mathrm{a}}{\mathrm{U}_{0}}, \theta=0$ and $\emptyset=0$ as $\eta \rightarrow \infty$

Where

$\alpha=\frac{\mathrm{k}}{\rho \mathrm{Cp}}, \operatorname{Re}_{\mathrm{x}}=\frac{\mathrm{u}_{\mathrm{w}} \mathrm{x}}{\mathrm{v}}$ and $\theta_{\mathrm{w}}=\frac{\mathrm{T}_{\mathrm{w}}}{\mathrm{T}_{\infty}}, \mathrm{Rd}=\frac{4 \sigma^{*}}{\mathrm{k}} \frac{\mathrm{T}_{\infty}^{3}}{\mathrm{k}^{*}}$,

$\mathrm{Du}=\frac{\mathrm{Dk}_{\mathrm{t}}\left(\mathrm{C}_{\mathrm{w}}-\mathrm{C}_{\infty}\right)}{\mathrm{C}_{\mathrm{s}} \mathrm{C}_{\mathrm{p}} v\left(\mathrm{~T}_{\mathrm{w}}-\mathrm{T}_{\infty}\right)}, v=\frac{\mu}{\rho^{\prime}}$

$\mathrm{Gr}_{\mathrm{C}}=\frac{\mathrm{g} \beta_{\mathrm{C}}\left(\mathrm{C}_{\mathrm{w}}-\mathrm{C}_{\infty}\right) \mathrm{x}^{3}}{v^{2}}$ and $\mathrm{Gr}_{\mathrm{T}}=\frac{\mathrm{g} \beta_{\mathrm{T}}\left(\mathrm{T}_{\mathrm{w}}-\mathrm{T}_{\infty}\right) \mathrm{x}^{3}}{v^{2}}$ are local Grashof number and local solutal Grashof number respectively. Also $\lambda=\frac{\mathrm{Gr}_{\mathrm{T}}}{\mathrm{Re}_{\mathrm{x}}^{2}}$ and $\delta=\frac{\mathrm{Gr}_{\mathrm{C}}}{\mathrm{Re}_{\mathrm{x}}^{2}}$ are thermal and solutal buoyancy parameters.

The physical quantities of practical interest are skin friction coefficient $\mathrm{C}_{\mathrm{f}}$, the local Nusselt number $\mathrm{Nu}_{\mathrm{x}}$ and the local Sherwood number $\mathrm{Sh}_{\mathrm{x}}$. These quantities are given as

$\mathrm{C}_{\mathrm{f}}=\frac{\tau_{\mathrm{w}}}{\rho \mathrm{u}_{\mathrm{w}}^{2}}, \mathrm{Nu}_{\mathrm{x}}=\frac{\mathrm{xq}_{\mathrm{w}}}{\mathrm{k}\left(\mathrm{T}_{\mathrm{w}}-\mathrm{T}_{\infty}\right)}, \mathrm{Sh}_{\mathrm{x}}=\frac{\mathrm{xq}_{\mathrm{m}}}{\mathrm{D}\left(\mathrm{C}_{\mathrm{w}}-\mathrm{C}_{\infty}\right)}$ 
Here

$\tau_{\mathrm{w}}=\mu\left(\frac{\partial \mathrm{u}}{\partial \mathrm{y}}\right)_{\mathrm{y}=0}, \mathrm{q}_{\mathrm{w}}=-\left[\left(\frac{16 \sigma^{*} \mathrm{~T}^{3}}{3 \mathrm{k}^{*}}+\mathrm{k}\right) \frac{\partial \mathrm{T}}{\partial \mathrm{y}}\right]_{\mathrm{y}=0}$

$\mathrm{q}_{\mathrm{m}}=-\left(\mathrm{D} \frac{\partial \mathrm{C}}{\partial \mathrm{y}}\right)_{\mathrm{y}=0}$

Now after using (9) and (14), we obtain

$\mathrm{C}_{\mathrm{f}} \operatorname{Re}_{\mathrm{x}}^{1 / 2}=\mathrm{f}^{\prime \prime}(0), \frac{\mathrm{Nu}_{\mathrm{x}}}{\sqrt{\mathrm{Re}_{\mathrm{x}}}}=-\frac{\left(1+\varepsilon+\frac{4}{3} \mathrm{Rd} \theta_{\mathrm{w}}^{3}\right) \theta^{\prime}(0)}{(1+\varepsilon \theta)}, \frac{\mathrm{Sh}_{\mathrm{x}}}{\sqrt{\mathrm{Re}_{\mathrm{x}}}}=-\emptyset^{\prime}(0)$

\section{NUMERICAL COMPUATION}

The system of boundary value problem (9)-(11) with boundary conditions has been solved with the help of Runge-Kutta Felberg method with shooting technique, by taking $\Delta \eta=0.01$ and $\eta_{\infty}=8$.

In this method firstly system of equations (9)-(11) with boundary conditions are reduced to the first order system by introducing new variables,

$$
\begin{gathered}
\mathrm{y}_{1}=\mathrm{f}, y_{2}=\mathrm{f}^{\prime}, y_{3}=\mathrm{f}^{\prime \prime} \\
\mathrm{y}_{4}=\theta, y_{5}=\theta^{\prime} \\
\mathrm{y}_{6}=\emptyset, y_{7}=\phi^{\prime} \\
\frac{d}{d \eta}\left(\begin{array}{l}
y_{1} \\
y_{2} \\
y_{3} \\
y_{4} \\
y_{5} \\
y_{6} \\
y_{7}
\end{array}\right)=\left(\begin{array}{l}
y_{2} \\
y_{3} \\
f^{\prime \prime \prime} \\
y_{5} \\
\theta^{\prime \prime} \\
y_{7} \\
\phi^{\prime \prime}
\end{array}\right)
\end{gathered}
$$

The converted boundary conditions are

$$
\mathrm{y}_{1}=0, \mathrm{y}_{2}=1, \mathrm{y}_{4}=1, \mathrm{y}_{6}=1 \text { at } \eta=0
$$

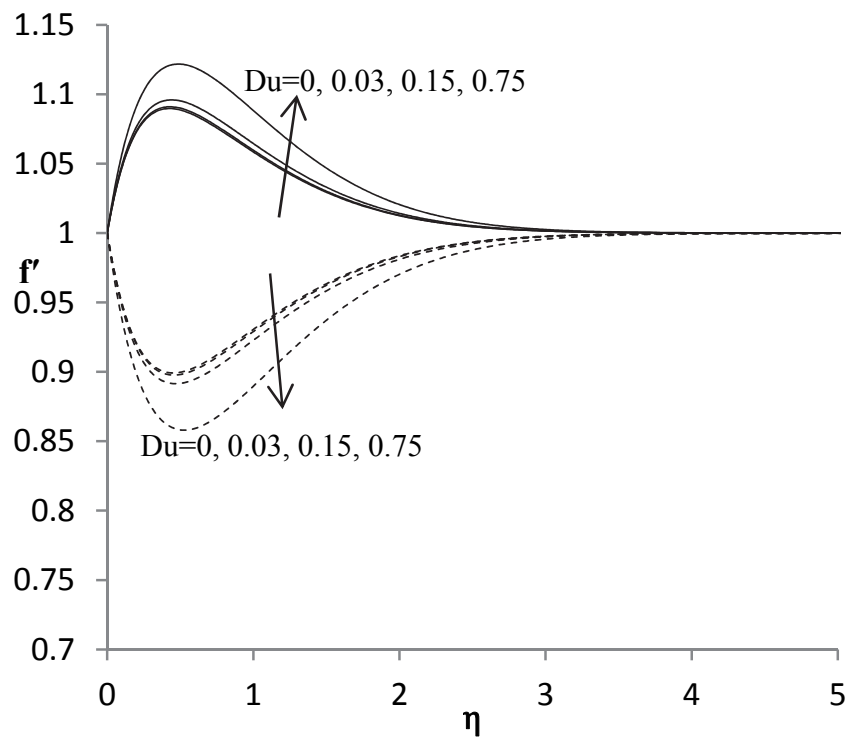

Fig. 2 Velocity profile with variable Dufour number $\left(\mathrm{Sc}=0.5, \mathrm{a} / \mathrm{U}_{0}=1, \mathrm{Pr}=7, \mathrm{Rd}=0.5, \lambda=1, \delta=0.5, \mathrm{M}=0.5\right.$, $\left.\theta_{\mathrm{w}}=1.1, \gamma=0.5\right)$

$$
y_{1}=\frac{a}{u_{0}}, y_{4}=0, y_{6}=0 \text { at } \eta \rightarrow \infty
$$

Here the missing initial conditions i.e. $y_{3}, y_{5}$ at $\eta=0$ are chosen in such a way so that the target values at $\eta \rightarrow \infty$ are satisfied by the boundary conditions. Then first order system of equation (16) with converted boundary values are solved with shooting method in the MATLAB software.

\section{RESULTS AND DISCUSSION}

These results are very good agreement with Pal (2009). The value of dimensionless velocity $\mathrm{f}^{\prime \prime}(\eta)$, dimensionless temperature $\theta(\eta)$ and dimensionless concentration $\Phi(\eta)$ have been computed for different values of dimensionless parameters and shown in figures 1-12. In all graphical results smooth curves presents the results for assisting fluid flow and dotted curve presents the results for opposing fluid flow.

Figure 2 show the effect of Dufour number on velocity profile. This figure depicted that magnitude of velocity increases with increasing values of Dufour number $(\mathrm{Du}=0,0.03,0.15,0.75)$, for both assisting and opposing flow. It is evident in the figure 2 and 3 that velocity increases with increase in the value of Dufour number and viscosity variation parameter, also attains a maximum value then it starts decreasing till the value becomes constant $(=1)$ for $\eta>3$ for both cases of opposing and assisting flow. In figure 3 it has been observed that magnitude of velocity increases with increasing values of viscosity variation parameter. Figure 4 presents the effect of Dufour number on temperature profile and show that magnitude of temperature increases with increasing values of Dufour number. It is also seen in the figure 4 that the temperature of the fluid decreases as the distance from the surface increases. In figure 5 it has been seen that magnitude of velocity decreases with increasing values of magnetic parameter $(\mathrm{M}=0,0.5,1,1.5)$ and attains its minimum value and then start decreasing till the value becomes constant $(=1)$ for $\eta>3$. From figures 6-8 effect of Prandtl number on temperature profile, concentration profile and on velocity profile have been presented. These figures show that magnitude of temperature, concentration and also magnitude of velocity decreases with increasing values of Prandtl number $(\operatorname{Pr}=0.7,7,10)$.

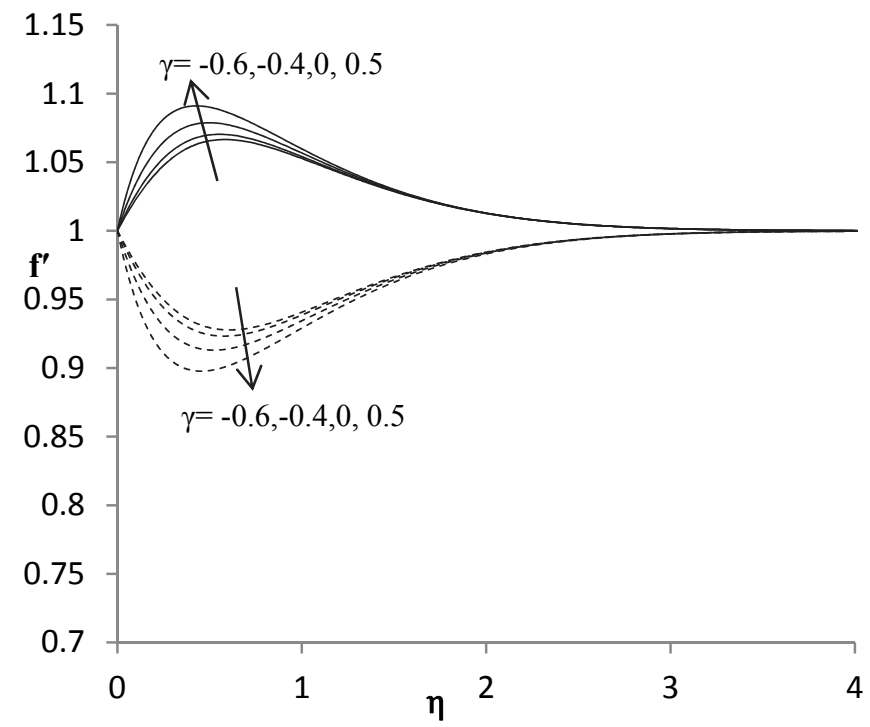

Fig. 3 Velocity profile with viscosity variation parameter $\left(\mathrm{Sc}=0.5, \mathrm{a} / \mathrm{U}_{0}=1, \mathrm{Pr}=7, \mathrm{Rd}=0.5, \lambda=1, \delta=0.5, \mathrm{M}=0.5\right.$, $\theta_{\mathrm{w}}=1.1, \mathrm{Du}=0.03$ ) 


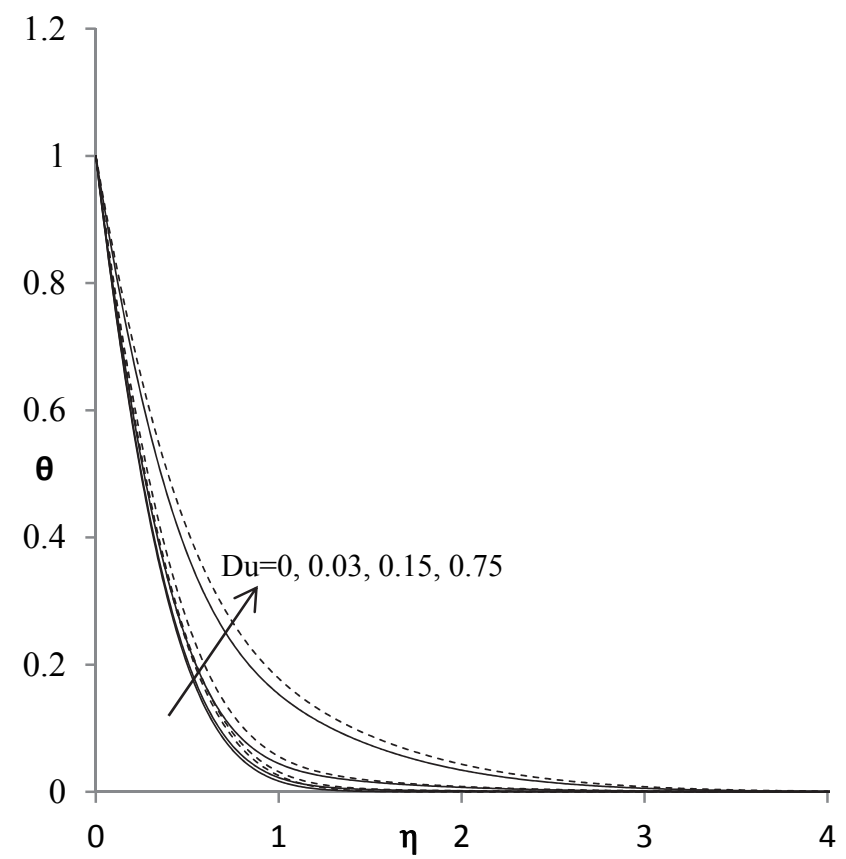

Fig. 4 Temperature profile with Dufour number $(\mathrm{Sc}=0.5$, $\mathrm{a} / \mathrm{U}_{0}=1, \operatorname{Pr}=7, \mathrm{Rd}=0.5, \lambda=1, \delta=0.5, \mathrm{M}=0.5, \theta_{\mathrm{w}}=1.1$, $\gamma=0.5$ )

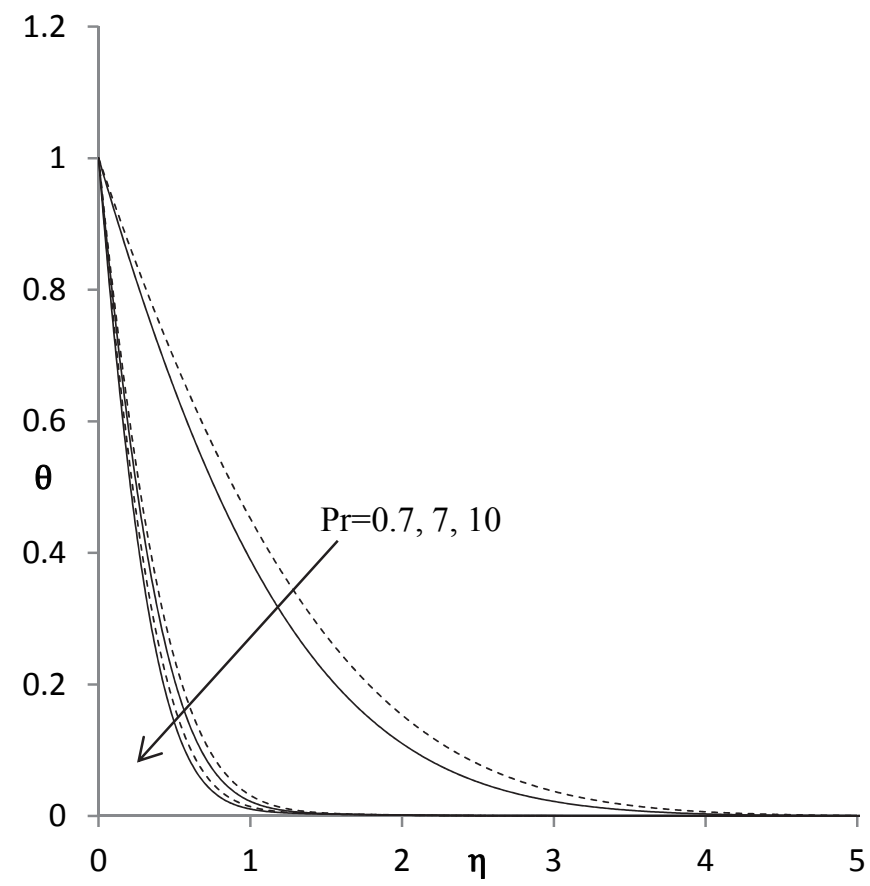

Fig. 6 Temperature profile with Dufour number $(\mathrm{Sc}=0.5$, $\mathrm{a} / \mathrm{U}_{0}=1, \mathrm{Du}=0.03, \mathrm{Rd}=0.5, \lambda=1, \delta=0.5, \mathrm{M}=0.5$, $\theta_{\mathrm{w}}=1.1, \gamma=0.5$ )

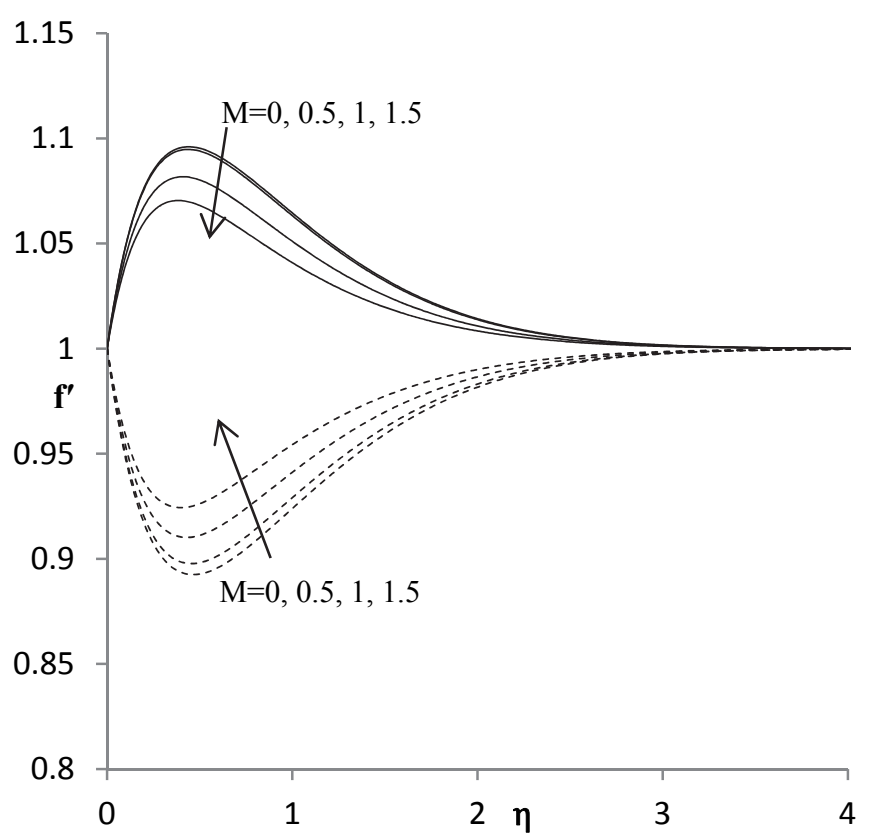

Fig. 5 Velocity profile with Magnetic parameter $(\mathrm{Sc}=0.5$, $\mathrm{a} / \mathrm{U}_{0}=1, \operatorname{Pr}=7, \mathrm{Rd}=0.5, \lambda=1, \delta=0.5, \mathrm{Du}=0.03$, $\left.\theta_{\mathrm{w}}=1.1, \gamma=0.5\right)$

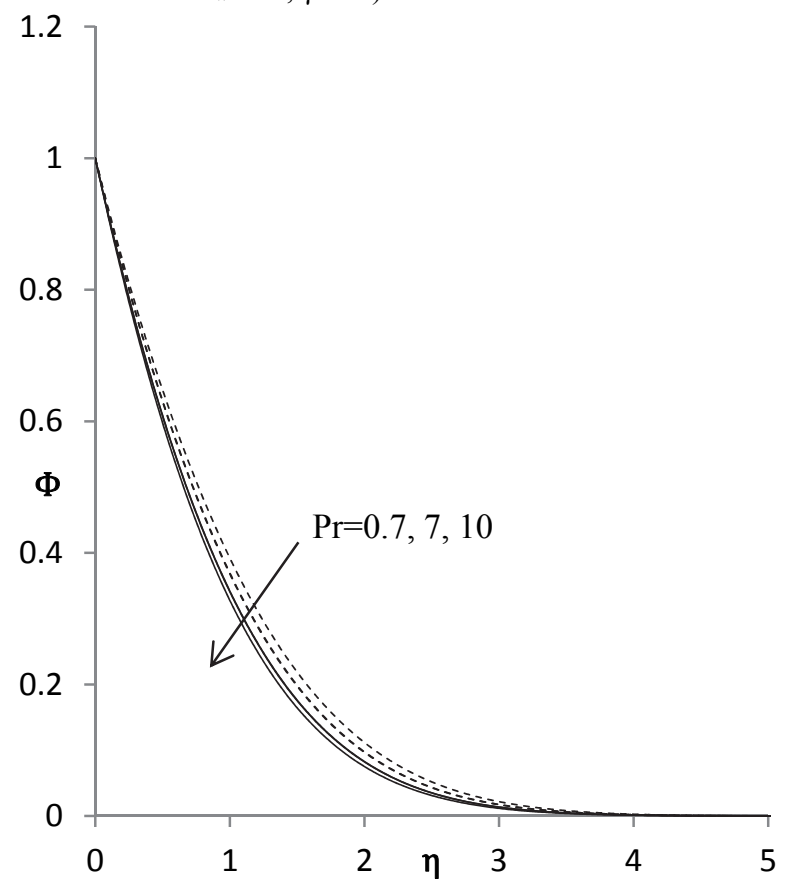

Fig. 7 Concentration profile with Magnetic parameter $\left(\mathrm{Sc}=0.5, \mathrm{a} / \mathrm{U}_{0}=1, \mathrm{Du}=0.03, \mathrm{Rd}=0.5, \lambda=1, \delta=0.5, \mathrm{M}\right.$ $=0.5, \theta_{\mathrm{w}}=1.1, \gamma=0.5$ ) 


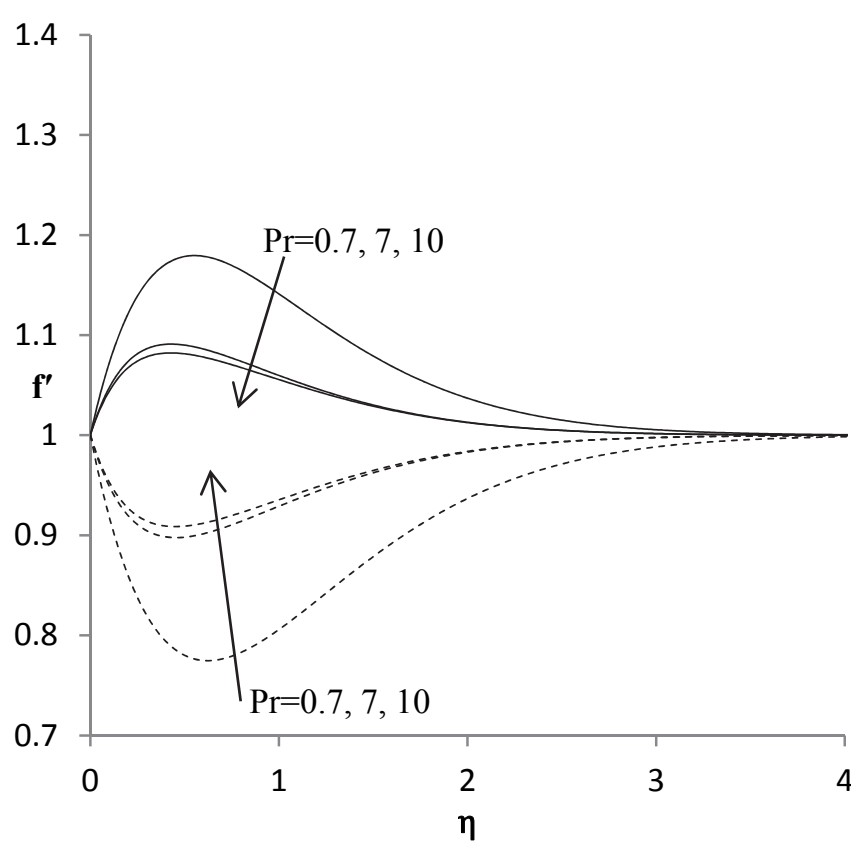

Fig. 8 Velocity profile with Prandtl number $(\mathrm{Sc}=0.5$, $\mathrm{a} / \mathrm{U}_{0}=1, \mathrm{Du}=0.03, \mathrm{Rd}=0.5, \lambda=1, \delta=0.5, \mathrm{M}=0.5$, $\left.\theta_{\mathrm{w}}=1.1, \gamma=0.5\right)$

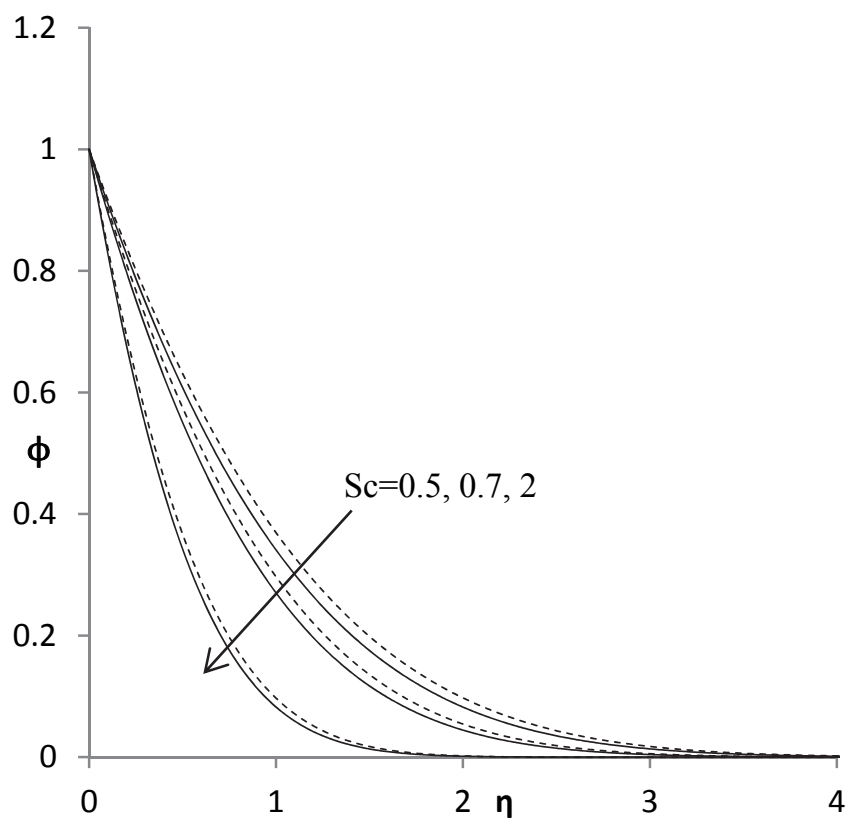

Fig. 10 Concentration profile with Schmidt number $(\mathrm{Pr}=7$, $\mathrm{a} / \mathrm{U}_{0}=1, \mathrm{Du}=0.03, \mathrm{Rd}=0.5, \lambda=1, \delta=0.5, \mathrm{M}=0.5$, $\left.\theta_{\mathrm{w}}=1.1, \gamma=0.5\right)$

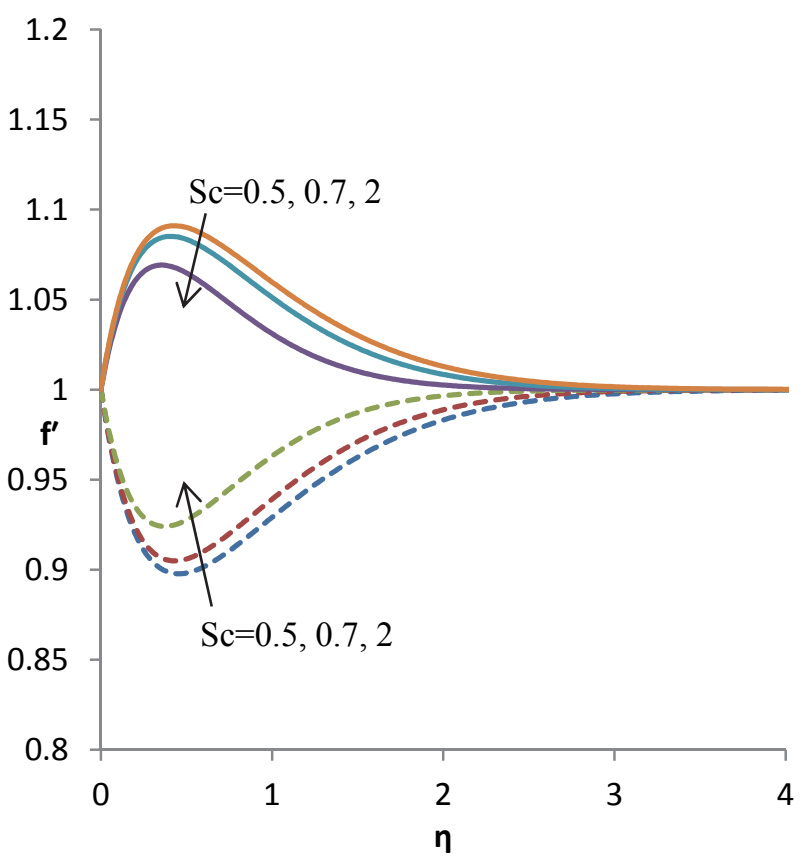

Fig. 9 Velocity profile with Schmidt number $(\mathrm{Pr}=7$, $\mathrm{a} / \mathrm{U}_{0}=1, \mathrm{Du}=0.03, \mathrm{Rd}=0.5, \lambda=1, \delta=0.5, \mathrm{M}=0.5$, $\theta_{\mathrm{w}}=1.1, \gamma=0.5$ )

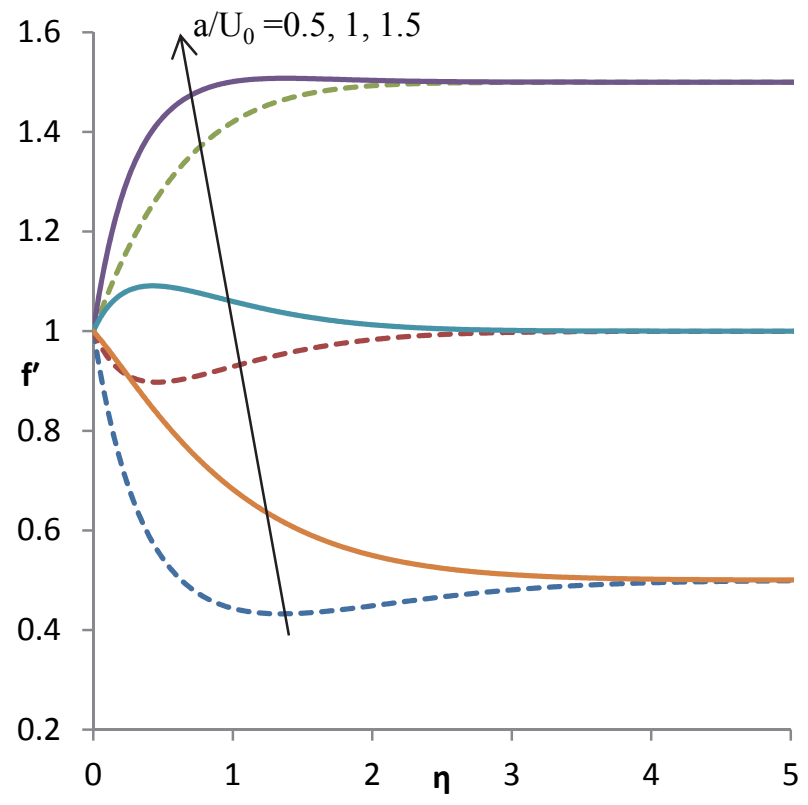

Fig. 11 Velocity profile with stretching velocity parameter $(\mathrm{Pr}=7, \mathrm{Sc}=0.5, \mathrm{Du}=0.03, \mathrm{Rd}=0.5, \lambda=1, \delta=0.5, \mathrm{M}$ $=0.5, \theta_{\mathrm{w}}=1.1, \gamma=0.5$ ) 


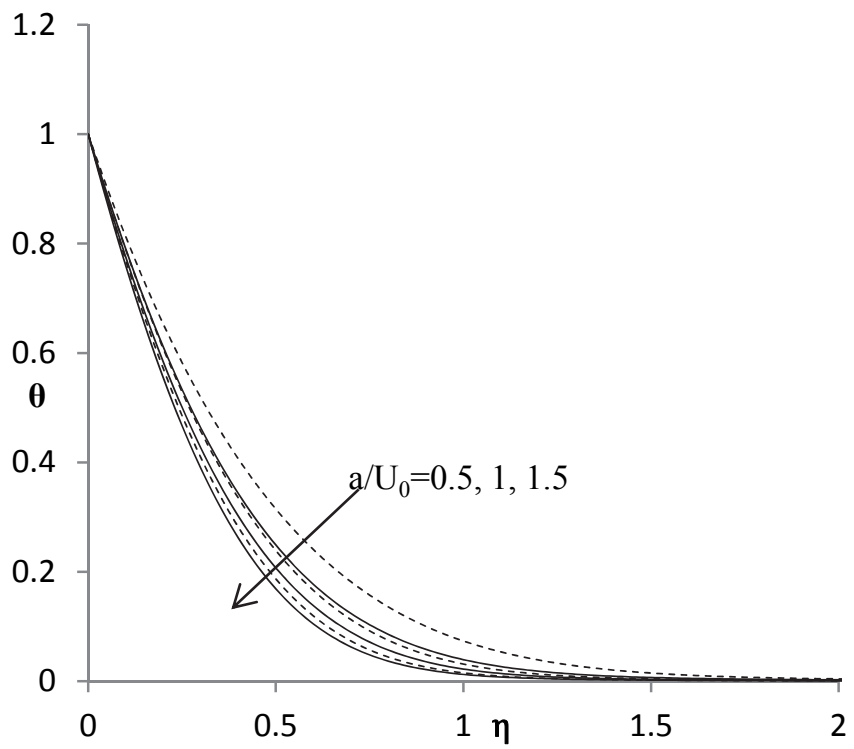

Fig. 12 Temperature profile with $\mathrm{a} / \mathrm{U}_{0} \quad(\mathrm{Pr}=7, \mathrm{Sc}=0.5$, $\mathrm{Du}=0.03, \mathrm{Rd}=0.5, \lambda=1, \delta=0.5, \mathrm{M}=0.5, \theta_{\mathrm{w}}=1.1$, $\gamma=0.5)$

Table 1: Values of skin friction coefficient, heat transfer coefficient and mass transfer coefficient with varying values of with different values of dimensionless parameters for assisting flow

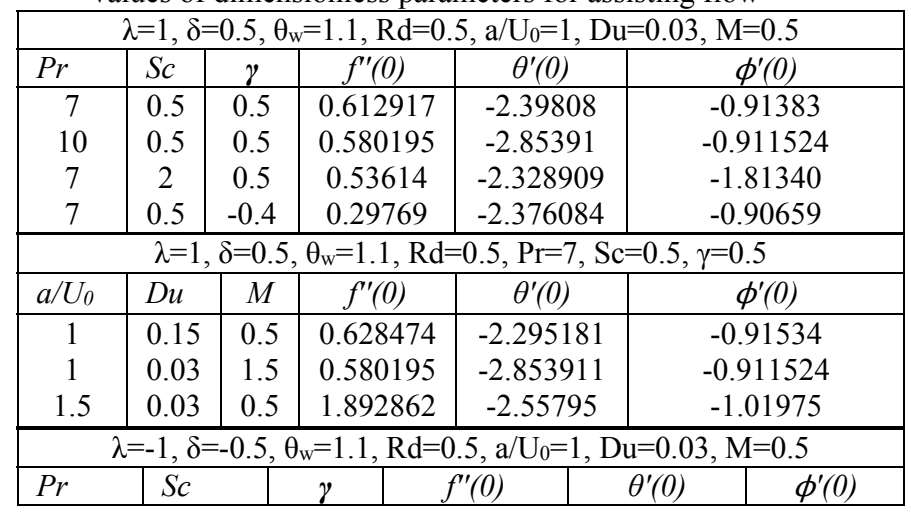

Figures 9 and 10 represent the effect of Schmidt number on velocity and concentration profile and show that magnitude of velocity and concentration both decreases with increasing values of Schmidt number $(\mathrm{Sc}=0.5,0.7,2)$. The effects of stretching velocity parameter on velocity, temperature and on concentration profiles have been presented in figures 11- 13. These figures show that magnitude of velocity increases, but magnitude of temperature and concentration decreases with increasing values of stretching velocity parameter $\left(\mathrm{a} / \mathrm{U}_{0}=0.5,1,1.5\right)$. Figure 11 depicts that for both cases of assisting and opposing flow a boundary layer is formed when stretching velocity is less than the free stream velocity i.e. when $a / U_{0}>1$. In the figure 11 it can also seen that the inverted boundary layer is formed for the case when $a / \mathrm{U}_{0}<1$ in both assisting and opposing flow. In figure 12 and 13 it is observed that the temperature as well as concentration increases with increase in $\mathrm{a} / \mathrm{U}_{0}$ for both assisting and opposing flow, also the values of temperature and concentration is higher for both opposing flow than for assisting flow at all points. It is also seen in the figures that the temperature and concentration of the fluid decreases as the distance from the surface is increased.

Tables 1 and 2 give the values of skin friction coefficient, heat transfer coefficient and mass transfer coefficient with different values of non dimensional parameters for both assisting and opposing flows.

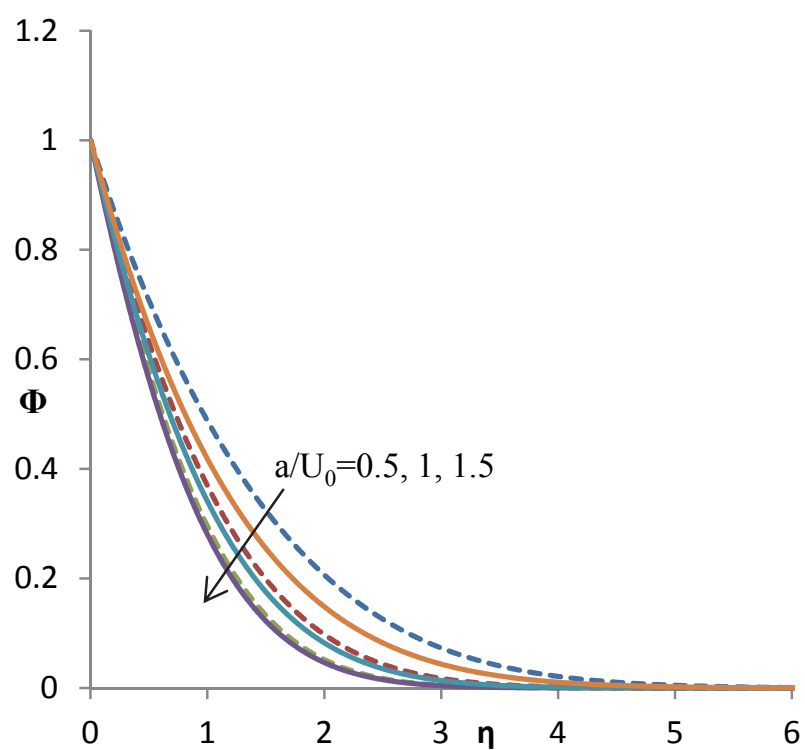

Fig. 13 Concentration profile with $\mathrm{a} / \mathrm{U}_{0} \quad(\mathrm{Pr}=7, \mathrm{Sc}=0.5$, $\mathrm{Du}=0.03, \mathrm{Rd}=0.5, \lambda=1, \delta=0.5, \mathrm{M}=0.5, \theta_{\mathrm{w}}=1.1$, $\gamma=0.5)$

Table 2: Values of skin friction coefficient, heat transfer coefficient and mass transfer coefficient with different values of dimensionless parameters for opposing flow

\begin{tabular}{|c|c|c|c|c|c|}
\hline 0.7 & 0.5 & 0.5 & -0.944669 & -0.68262 & -0.81588 \\
10 & 0.5 & 0.5 & -0.610268 & -2.71765 & -0.85735 \\
7 & 2 & 0.5 & -0.56214 & -2.224077 & - \\
7 & 0.5 & -0.6 & -0.261985 & -2.29527 & 1.726344 \\
& & & & & -0.86515 \\
\hline \multicolumn{5}{|c|}{$\lambda=-1, \delta=-0.5, \theta_{\mathrm{w}}=1.1, \mathrm{Rd}=0.5, \mathrm{Pr}=7, \mathrm{Sc}=0.5, \gamma=0.5$} \\
\hline$a / U_{0}$ & $D u$ & $M$ & $f^{\prime \prime}(0)$ & $\theta^{\prime}(0)$ & $\phi^{\prime}(0)$ \\
\hline 1 & 0.75 & 0.5 & -0.757682 & -1.64294 & -0.84167 \\
1 & 0.03 & 1.5 & -0.548368 & -2.27973 & - \\
1.5 & 0.03 & 0.5 & 0.766956 & -2.46399 & 0.862883 \\
& & & & & -0.98077 \\
\hline
\end{tabular}

\section{CONCLUSIONS}

Results shows that magnitude of skin friction coefficient decreases, while magnitude of heat transfer coefficient and mass transfer coefficient increases with decreasing values of viscosity variation parameter for the case of opposing flow. But in the case of assisting flow magnitude of skin friction coefficient, heat transfer coefficient and mass transfer coefficient decreases with decreasing values of viscosity parameter. It has been observed that, magnitude of skin friction coefficient and heat transfer coefficient decreases with increasing values of Dufour number for both assisting and opposing flow, and there is a slight change in magnitude of mass transfer coefficient with Dufour number. Further it has been noticed that magnitude of skin friction coefficient and heat transfer coefficient decreases with increasing values of magnetic parameter for both observed cases. With increasing values of Prandtl number magnitude of skin friction coefficient decreases but magnitude of heat transfer coefficient increases for both cases of assisting and opposing flows. It has been seen that with mass transfer parameter magnitudes of skin friction coefficient and heat transfer coefficient decreases but magnitude of mass transfer coefficient increases for both considered cases. 


\section{ACKNOWLEDGEMENTS}

The author wish to express her very sincere thanks to the reviewers and editor of journal for their valuable comments and suggestions which improved the quality of the paper.

\section{NOMENCLATURE}

\begin{tabular}{ll}
$\mathrm{u}$ & velocity component along $\mathrm{x}$ direction \\
$\mathrm{v}$ & velocity component along y direction \\
$\mathrm{g}$ & acceleration due to gravity \\
$\mathrm{T}$ & temperature of fluid \\
$\mathrm{C}$ & concentration of fluid \\
$\psi$ & stream function \\
$\eta$ & similarity variable \\
$\theta$ & Dimensionless temperature \\
$\varnothing$ & Dimensionless concentration \\
$\mathrm{u}_{\mathrm{w}}(\mathrm{x})$ & stretching velocity \\
$\mathrm{T}_{\mathrm{w}}(\mathrm{x})$ & surface temperature \\
$\mathrm{C}_{\mathrm{w}}(\mathrm{x})$ & surface concentration \\
$\mathrm{a} / \mathrm{U}_{0}$ & stretching velocity parameter \\
$\mathrm{k}$ & thermal conductivity of fluid \\
$\mu^{\prime}$ & variable fluid viscosity \\
$\mathrm{K}_{\mathrm{t}}$ & thermal diffusion ratio \\
$\mathrm{D}$ & mass diffusion coefficient \\
$\mathrm{T}_{\infty}$ & free stream temperature \\
$\mathrm{C}_{\infty}$ & free stream concentration \\
$\mathrm{V}_{\mathrm{w}}$ & suction velocity \\
$\mathrm{u}_{\mathrm{e}}$ & velocity of the flow external to the boundary layer \\
$\mathrm{M}$ & magnetic parameter \\
$\mathrm{Rd}_{\mathrm{Sc}}$ & Radiation Parameter \\
$\mathrm{Sc}$ & Schmidt number \\
$\mathrm{Du}$ & Dufour number \\
$\mathrm{Pr}$ & Prandtl number \\
$\lambda$ & thermal buoyancy parameter \\
$\delta$ & solutal buoyancy parameter \\
$\gamma$ & non dimensional viscosity variation parameter. \\
$\mathrm{C}_{\mathrm{f}}$ & skin friction coefficient \\
$\mathrm{Nu}_{\mathrm{x}}$ & local Nusselt number \\
$\mathrm{Sh}$ & local Sherwood number \\
$\mathrm{Gr}_{\mathrm{C}}$ & local Grashof number \\
$\mathrm{Gr}_{\mathrm{T}}$ & local solutal Grashof number \\
& \\
\hline &
\end{tabular}

\section{REFERENCES}

Alam, M. S. and Rahman, M. M., 2006, "Dufour and Soret Effects on Mixed Convection Flow Past a Vertical Porous Flat Plate with Variable Suction," Nonlinear Analysis: Modelling and Control, 11(1), 3-12.

Chamkha, Ali J. and Ben- Nakhi, Abdullatif, 2008, "MHD Mixed Convection - Radiation Interaction Along a Permeable Surface Immersed in a Porous Medium in the Presence of Soret and Dufour's Effects," Heat and Mass Transfer, 44, 845-856.

http://dx.doi.org/10.1007/s00231-007-0296-x

Eckert, E. R. G. and Drake, R. M., 1972, “Analysis of heat \& mass transfer," McGraw Hill, New York.

El- Aziz, M. A., 2007, “Temperature Dependent Viscosity and Thermal Conductivity Effects on Combined Heat and Mass Transfer in MHD
Three-Dimensional Flow Over a Stretching Surface with Ohmic Heating," Meccanica, 42, 375- 386.

http://dx.doi.org/10.1007/s11012-006-9051-5

El-Mistikawy, M. A. T., 2016, "MHD Flow Due to a Linearly Stretching Sheet with Induced Magnetic Field," Acta Mechanica. http://dx.doi.org/10.1007/s00707-016-1643-0

Ishak, A., Nazar, R., and Pop, I., 2006, "Mixed Convection Boundary Layers in the Stagnation-Point Flow towards a Stretching Vertical Sheet," Meccanica, 41, 509- 518.

http://dx.doi.org/10.1007/s11012-006-0009-4

Ishak, A., Nazar, R., and Pop. I., 2008, "Hydromagnetic Flow and Heat Transfer Adjacent to a Stretching Vertical Sheet," Heat and Mass Transfer, 44, 921-927.

http://dx.doi.org/10.1007/s00231-007-0322-z

Mahapartra, T. R. and Gupta, A. S., 2002, "Heat Transfer in StagnationPoint Flow towards a Stretching Sheet," Heat and Mass Transfer, 38, 517-521.

http://dx.doi.org/10.1007/s002310100215

Mohamed, M. K. A., Salleh, M. Z., Nazar, R., Ishak, A., 2013, "Numerical Investigation of Stagnation Point Flow over a Stretching Sheet with Convective Boundary Conditions," Boundary Value Problems, 4, 1-10.

http://dx.doi.org/10.1186/1687-2770-2013-4

Pal, D., 2009, "Heat and Mass Transfer in Stagnation Point Flow Towards a Stretching Surface in the Presence of Buoyancy Force and Thermal Radiation," Meccanica, 44, 145- 158. http://dx.doi.org/10.1007/s11012-008-9155-1

Raptis, A., 1998, "Radiation and Free Convection Flow Through a Porous Medium," Int Commun Heat Mass Transf, 25, 289-295. http://dx.doi.org/10.1016/s0735-1933(98)00016-5

Salem, A. M., Fathy, R., 2012, "Effects of Variable Properties on MHD Heat and Mass Transfer Flow Near a Stagnation Point Towards a Stretching Sheet in a Porous Medium with Thermal Radiation," Chinese Physics, 21(5), 054701

http://dx.doi.org/10.1088/1674-1056/21/5/054701

Schlichting, H., 1968, “Boundary Layer Theory," Fourth Edition, McGraw-Hill, New York.

Sparrow, E. M. and Cess, R. D., 1978, "Radiation heat transfer," Hemisphere, Washington.

Seedeek, M. A. and Salem, A. M., 2005, "Laminar Mixed Convection Adjacent to Vertical Continuously Stretching Sheets with Variable Viscosity and Variable Thermal Diffusivity," Heat and mass transfer, 41, 1048-1055.

http://dx.doi.org/10.1007/s00231-005-0629-6 